\title{
Flood Risk Zoning by Using 2D Hydrodynamic Modeling: A Case Study in Jinan City
}

\author{
Tao Cheng, ${ }^{1,2}$ Zongxue Xu, ${ }^{1,2}$ Siyang Hong, ${ }^{1,2}$ and Sulin Song ${ }^{3}$ \\ ${ }^{1}$ College of Water Sciences, Beijing Normal University, Beijing 100875, China \\ ${ }^{2}$ Beijing Key Laboratory of Urban Hydrological Cycle and Sponge City Technology, Beijing 100875, China \\ ${ }^{3}$ Jinan Hydrology Bureau, Jinan 250014, China
}

Correspondence should be addressed to Zongxue Xu; zongxuexu@vip.sina.com

Received 30 June 2017; Accepted 6 September 2017; Published 12 October 2017

Academic Editor: Jian G. Zhou

Copyright (C) 2017 Tao Cheng et al. This is an open access article distributed under the Creative Commons Attribution License, which permits unrestricted use, distribution, and reproduction in any medium, provided the original work is properly cited.

\begin{abstract}
Climate change and rapid urbanization have aggravated the rainstorm flood in Jinan City during the past decades. Jinan City is higher in the south and lower in the north with a steep slope inclined from the south to the north. This results in high-velocity overland flow and deep waterlogging, which poses a tremendous threat to pedestrians and vehicles. Therefore, it is vital to investigate the rainstorm flood and further perform flood risk zoning. This study is carried out in the "Sponge City Construction" pilot area of Jinan City, where the InfoWorks ICM 2D hydrodynamic model is utilized for simulating historical and designed rainfall events. The model is validated with observations, and the causes for errors are analyzed. The simulated water depth and flow velocity are recorded for flood risk zoning. The result shows that the InfoWorks ICM 2D model performed well. The flood risk zoning result shows that rainfalls with larger recurrence intervals generate larger areas of moderate to extreme risk. Meanwhile, the zoning results for the two historical rainfalls show that flood with a higher maximum hourly rainfall intensity is more serious. This study will provide scientific support for the flood control and disaster reduction in Jinan City.
\end{abstract}

\section{Introduction}

During the past decades, Jinan City has experienced prosperity in social economy. However, a series of urban water problems such as water pollution, water shortage, and urban flooding have arisen and posed a great challenge to the continued healthy development of social society $[1,2]$. Severe climate change and rapid urbanization augment the probability of urban rainstorm flood and cause a large number of casualties and economic losses [3, 4]. Urban rainstorm flood has become one of the most concerning problems $[5,6]$. In order to strengthen the work of flood control and disaster reduction and reduce the casualty and property losses caused by urban floods, it has become an increasingly common method to use the urban flood model to simulate the flooding situation and perform flood risk zoning which provides technical support for flood control and disaster reduction [7-10]. At present, many Chinese scholars have used hydrological and hydraulic models to carry out a lot of researches on the urban flooding problem and have accumulated abundant theoretical and practical experience for flood prevention and reduction work in our country $[8,11]$. Since the 1980 s, a group of Chinese scholars have developed urban rain-flood models with independent intellectual property rights, but these models are usually codes or programs used within a number of research teams. These models are not easy to operate or interface friendly, and they are not widely used for the lack of commercial promotion [8]. In comparison, the SWMM model from the United States is broadly used because its codes are open-source and it is free to use [12]. MIKE series (Denmark), InfoWorks ICM (UK), and PCSWMM (Canada) also have a good number of users due to their strong hydrodynamic ability and preprocessing and postprocessing capacity $[4,13]$. Yu et al. [14] developed an urban flood model of city scale in Jinan City by using the SWMM model. The results are good and the work has provided scientific and technological support for flood control and disaster reduction in Jinan City. Huang et al. [15] used the 
InfoWorks ICM model to develop an integrated catchment model of urban scale in Haikou City. The model has been verified with monitoring data and the results have shown that the model has good accuracy and reliability. Wu and Huang [16] used the PCSWMM model to develop a rainflood model which has been verified with observed data and used for analyzing the risk for designed rainfalls of different recurrence intervals. Qi et al. [17] developed a onedimensional and a two-dimensional hydrodynamic model in the lower reaches of Tiantang River of Beijing based on MIKE 11 and MIKE 21. Then, these models have been coupled using MIKE FLOOD to simulate the regional flood under different rainstorm scenarios. The flood risk has been analyzed and has provided scientific support for the rational selection of the detention area and the development of a proper dam control scheme.

Jinan City has repeatedly suffered extreme rainstorms in history. Its flood problem is very severe due to its special geography. The city is higher in the south and lower in the north, so road flood and waterlogging have become a main threat to pedestrians and vehicles $[1,14]$. This paper intends to use InfoWorks ICM to develop a model coupling hydrological with hydrodynamic process in the "Sponge City Construction" pilot area of Jinan City. Several historical rainstorm events are modeled and verified with the flood monitoring records. Then, the verified model is used for designed rainfalls of different recurrence intervals. The water depth and velocity are recorded and used to perform flood risk zoning. This work will provide scientific and technological support for flood prevention and mitigation work of the study area and Jinan City as well.

\section{Methodologies}

2.1. Coupled Hydrological and Hydrodynamic Model. The coupled hydrological and hydrodynamic model based on InfoWorks ICM consists of a hydrological process and a hydrodynamic process and their coupled process. As we know, the hydrodynamic modeling, especially the two-dimensional hydrodynamic modeling, is very timeconsuming and always a bottleneck for fast and detailed modeling. The InfoWorks ICM can solve this problem with its parallel computation based on GPUs. Moreover, table handling, SQL query, and GIS function are available in the InfoWorks ICM, which make it easier for data preprocessing and result postprocessing.

The processes included in the InfoWorks ICM are the runoff calculation and flow convergence for the hydrological model, the one-dimensional hydrodynamic simulation for the underground pipe networks, and the two-dimensional hydrodynamic simulation for surface inundation. The hydrological model adopts a distributed method to simulate the rainfall-runoff process by dividing the study area into detailed subcatchment areas which may have various runoff surfaces of different flow characteristics. The runoff calculation and flow convergence process of the hydrological model can employ various models. In this paper, the fixed runoff model and SWMM flow convergence model are employed, respectively, as the object of our study is the urban area.
The hydrodynamic simulation for the underground pipe networks is implemented by solving the Saint-Venant equations. The flow in the underground pipes has two states, that is, surface flow and pressurized flow, and the Preissmann Slot is used to handle both kinds of flow and their transition. The mathematical expressions of the Saint-Venant equations are shown in

$$
\begin{array}{r}
\frac{\partial A}{\partial t}+\frac{\partial Q}{\partial x}=0, \\
\frac{\partial Q}{\partial t}+\frac{\partial}{\partial x}\left(\frac{Q^{2}}{A}\right)+g A\left(\cos \theta \frac{\partial h}{\partial x}-S_{0}+\frac{Q|Q|}{K^{2}}\right)=0,
\end{array}
$$

where $A$ is the cross-sectional area of the pipe $\left(\mathrm{m}^{2}\right) ; \mathrm{Q}$ is the flow rate of the pipe $\left(\mathrm{m}^{3} \cdot \mathrm{s}^{-1}\right) ; t$ is time $(\mathrm{s}) ; x$ is the length along the $x$ direction $(\mathrm{m}) ; h$ is water depth $(\mathrm{m}) ; g$ is gravity $\left(\mathrm{m} \cdot \mathrm{s}^{-2}\right) ; \theta$ is the angle between the pipe line and horizontal line (degree); $K$ is the conveyance and is calculated with Colebrook-White formula or Manning formula; $S_{0}$ is the bed slope.

The two-dimensional hydrodynamic simulation of the surface inundation is implemented by solving the shallow water equations (SWE), which are based on the depthaveraged Navier-Stokes equations. The assumption of these equations is that the flow is mainly in the horizontal direction, while flow rate changes in the vertical direction are negligible. The mathematical expressions of the shallow water equations are shown in

$$
\begin{aligned}
& \frac{\partial h}{\partial t}+\frac{\partial(h u)}{\partial x}+\frac{\partial(h v)}{\partial y}=q_{1 D} \\
& \frac{\partial(h u)}{\partial t}+\frac{\partial}{\partial x}\left(h u^{2}+\frac{g h^{2}}{2}\right)+\frac{\partial(h u v)}{\partial y} \\
& =S_{0, x}-S_{f, x}+q_{1 D} u_{1 D}, \\
& \frac{\partial(h v)}{\partial t}+\frac{\partial}{\partial y}\left(h v^{2}+\frac{g h^{2}}{2}\right)+\frac{\partial(h u v)}{\partial x} \\
& =S_{0, y}-S_{f, y}+q_{1 D} v_{1 D},
\end{aligned}
$$

where $u$ and $v$ are the velocity component in the $x$ and $y$ directions $\left(\mathrm{m} \cdot \mathrm{s}^{-1}\right) ; S_{0, x}$ and $S_{0, y}$ are the bed slope component in the $x$ and $y$ directions $\left(\mathrm{m}^{2} \cdot \mathrm{s}^{-2}\right) ; S_{f, x}$ and $S_{f, y}$ are the friction component in the $x$ and $y$ directions $\left(\mathrm{m}^{2} \cdot \mathrm{s}^{-2}\right) ; q_{1 D}$ is the outflow per unit area $\left(\mathrm{m} \cdot \mathrm{s}^{-1}\right) ; u_{1 D}$ and $v_{1 D}$ are the velocity component of $q_{1 D}$ in the $x$ and $y$ directions $\left(\mathrm{m} \cdot \mathrm{s}^{-1}\right)$; other variables not stated here are the same as above.

2.2. Flood Risk Zoning. There is a broad consensus that the degree of flood risk that flood poses to people (as well as vehicles, buildings, etc.) is a function of velocity and depth. Other physical factors such as water temperature, land surface type, and objects that may cause slippage or fall (e.g., "blown" manhole), are likely to have an impact on the risk for people or objects in the flood. Xia et al. [18, 19] and Milanesi et al. [20, 21] developed risk calculation methods 


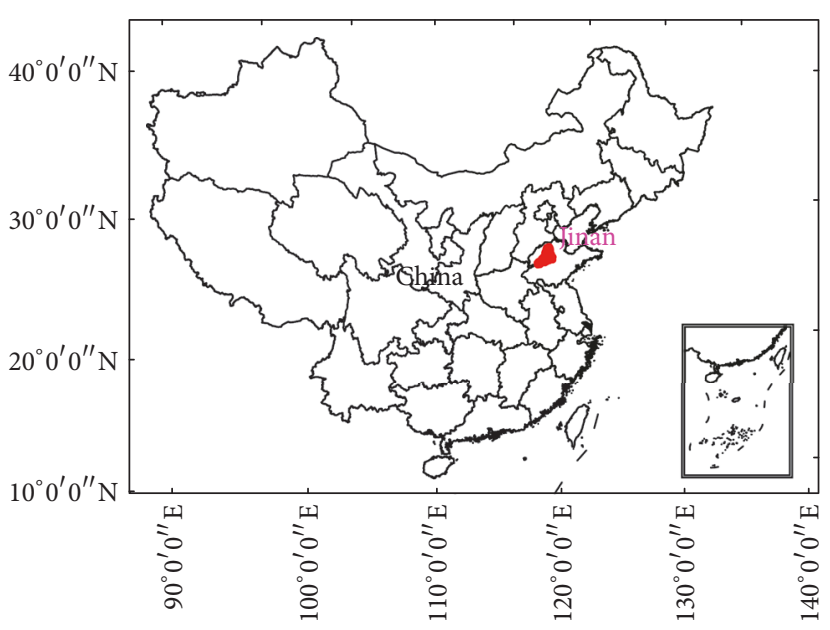

(a)

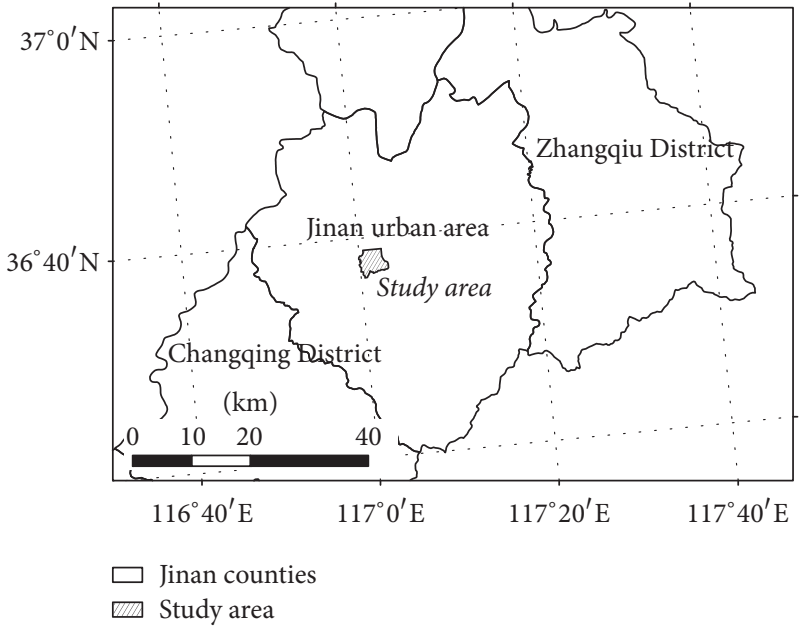

(b)

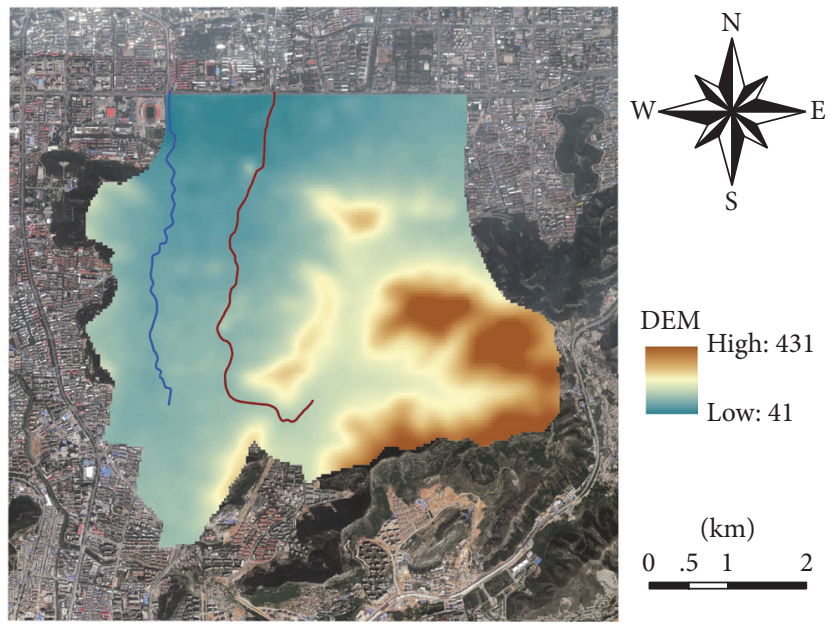

- Liyang River

Yuxiu River

(c)

FIgURE 1: Location of the study area. (a) The overall location of Jinan City in China. (b) The location of the study area in Jinan City. (c) The layout of the study area where two rivers and the DEM are shown.

of the human body or vehicles through rigorous mechanical analyses and human engineering. However, these methods are based on complicated theoretical formula deduction, restricting their convenient and efficient applications. In this paper, the empirical method of calculating the flood risk recommended by Defra/Environment Agency of the United Kingdom [22] will be used, and the corresponding formula is shown as

$$
\mathrm{HR}=h \times(U+0.5)+\mathrm{DF},
$$

where HR is the flood risk value; $h$ is water depth $(\mathrm{m}) ; U$ is the velocity of floodwater $\left(\mathrm{m} \cdot \mathrm{s}^{-1}\right)$; DF is the debris factor $(=0$, 0.5 , or 1 depending on the probability that debris will lead to a significantly greater hazard, shown in Table 1).

The risk values calculated with the above formula will be classified and a detailed classification is shown in Table 2.
TABLE 1: Debris factors for different flood depths, velocities, and dominant land uses.

\begin{tabular}{lccc}
\hline Depth $(\mathrm{m})$ \& velocity $\left(\mathrm{m} \cdot \mathrm{s}^{-1}\right)$ & Pasture/arable & Woodland & Urban \\
\hline $0<h \leq 0.25$ & 0 & 0 & 0 \\
$0.25<h \leq 0.75$ & 0 & 0.5 & 1 \\
$h>0.75$ or $v>2$ & 0.5 & 1 & 1 \\
\hline
\end{tabular}

\section{Model Application}

3.1. Study Area Description. Jinan is the political, economic, and cultural center of Shandong Province of China. The study area (as shown in Figure 1) is situated in the south of the main urban area of Jinan City, where the Liyang River and the Yuxiu River go through and the "Sponge City Construction" pilot area is located. The eastern, western, and southeastern 
TABLE 2: Classification of risk levels.

\begin{tabular}{|c|c|c|}
\hline HR & Degree of flood risk & Description \\
\hline \multirow{2}{*}{$0,0.75$} & \multirow{2}{*}{ Low } & Caution \\
\hline & & Flood zone with shallow flowing water or deep standing water \\
\hline \multirow{2}{*}[0.75,1.25]{} & \multirow{2}{*}{ Moderate } & Dangerous for some (i.e., children) \\
\hline & & "Danger: flood zone with deep or fast flowing water" \\
\hline \multirow{2}{*}{$(1.25,2.5]$} & \multirow{2}{*}{ Significant } & Dangerous for most people \\
\hline & & "Danger: flood zone with deep fast flowing water" \\
\hline \multirow{2}{*}{$2.5, \infty$} & \multirow{2}{*}{ Extreme } & Dangerous for all \\
\hline & & "Extreme danger: flood zone with deep fast flowing water" \\
\hline
\end{tabular}

TABLE 3: Parameter attributes for three kinds of surfaces.

\begin{tabular}{ccccccccccccccc}
\hline Number & Surface type & $\begin{array}{c}\text { Runoff } \\
\text { model }\end{array}$ & $\begin{array}{c}\text { Runoff } \\
\text { coefficient }\end{array}$ & Surface type & $\begin{array}{c}\text { Initial losses } \\
\text { type }\end{array}$ & $\begin{array}{c}\text { Initial losses } \\
(\mathrm{mm})\end{array}$ & $\begin{array}{c}\text { Routine } \\
\text { model }\end{array}$ & $\begin{array}{c}\text { Routine } \\
\text { type }\end{array}$ & $\begin{array}{c}\text { Routine } \\
\text { parameter }\end{array}$ & $\begin{array}{c}\text { Area } \\
\text { (ha) }\end{array}$ \\
\hline 1 & Road & $\begin{array}{c}\text { Fixed PR } \\
\text { model }\end{array}$ & 0.95 & Impervious & Constant & 2 & SWMM & Relative & 0.018 & 127.1 \\
2 & Roof & $\begin{array}{c}\text { Fixed PR } \\
\text { model }\end{array}$ & 0.90 & Impervious & Constant & 1 & SWMM & Relative & 0.020 & 231.1 \\
3 & Others & $\begin{array}{c}\text { Fixed PR } \\
\text { model }\end{array}$ & 0.60 & Pervious & Constant & 5 & SWMM & Relative & 0.025 & 2014.5 \\
\hline
\end{tabular}

parts of the study area are characterized by mountains and hills. The area inclines from the south to the north, with a maximum slope of $35.77 \%$ and an average slope of $6.8 \%$. This area has been planned and constructed ages ago, and the drainage capacity of the underground drainage pipe networks is insufficient. The huge body of water from the southern mountainous area in the fluvial season will easily form a rapid flood in the study area. Jinan is characterized by a semihumid continental monsoon climate, and so is the study area. Rainfall averages at 500 and $600 \mathrm{~mm}$ and is unevenly distributed during the year. Heavy rain events usually occur from July to August in the summer. The distribution of a rain event is concentrated and mainly happens in 12 hours, which generally accounts for more than $80 \%$ of the total amount.

3.2. Setup of InfoWorks ICM. The Thiessen polygon method is used to divide the subcatchments of which the runoff will flow into the nearest manholes. Through this way, the hydrological model for surface runoff is connected with the one-dimensional hydrodynamic model for the pipe network. Meanwhile, the hydrodynamic model for the underground pipe network is connected with the two-dimensional hydrodynamic model for surface inundation by setting the flood type of manholes as " $2 \mathrm{D}$." This means the water exchange between the surface and manholes is calculated using standard weir equations, where the weir width is taken as the circumference of the manholes. When the drainage capacity is insufficient, the surface is flooded by overflow from the manholes, and in turn the water on the ground will return to the pipe network through the manholes if the drainage network capacity is restored. This way, the coupled model simulates the water exchange between these simulation processes.
The cell size of the two-dimensional hydrodynamic model is set to be less than $50 \mathrm{~m}^{2}$ for road areas and between 50 and $100 \mathrm{~m}^{2}$ for other areas. The exact cell size for each mesh is decided by the boundary and topography and is generated with a grid generator embedded in the InfoWorks ICM.

The hydrological model mainly contains parameters for the runoff process and flow convergence process. The parameter is the roughness of the pipe walls for the one-dimensional pipe network model and the roughness of the surfaces for the two-dimensional hydrodynamic model. These parameters are set and adjusted mainly referring to the InfoWorks ICM help document [23] and other related researches [1, 24-26].

\section{Result Analysis and Discussion}

4.1. Model Calibration and Validation. We have gathered historical rainfalls and surface inundation records only for 2013-07-23 and 2015-08-03 rainfall events, of which the inundation record for 2015-08-03 is comparatively complete. Therefore, the record for 2015-08-03 is used for parameter calibration, and the record for 2013-07-23 is used for parameter validation. As the InfoWorks ICM cannot perform parameters autoverification and is not feasible for secondary development, the parameters are adjusted manually. Through parameter calibration and validation, the rational parameters values are finally obtained. The roughness of the pipe walls is 0.013 , and the roughness of the surface is 0.025 . Parameters values of the hydrological model are shown in Table 3.

Figures 2(a) and 2(b), respectively, show the hydrograph of surface inundation for parameters calibration and validation. It can be seen from Figure 2(a) that the simulated maximum water depth for 2015-08-03 rainfall event is $0.078 \mathrm{~m}$ and occurs at 20:05, well in accord with the observed record. 


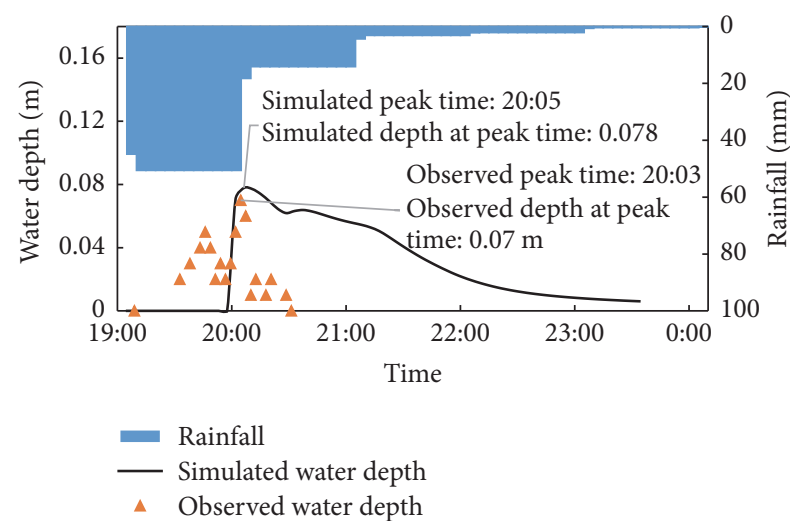

(a) The simulated water depth hydrograph for 2015-08-03 rainfall event

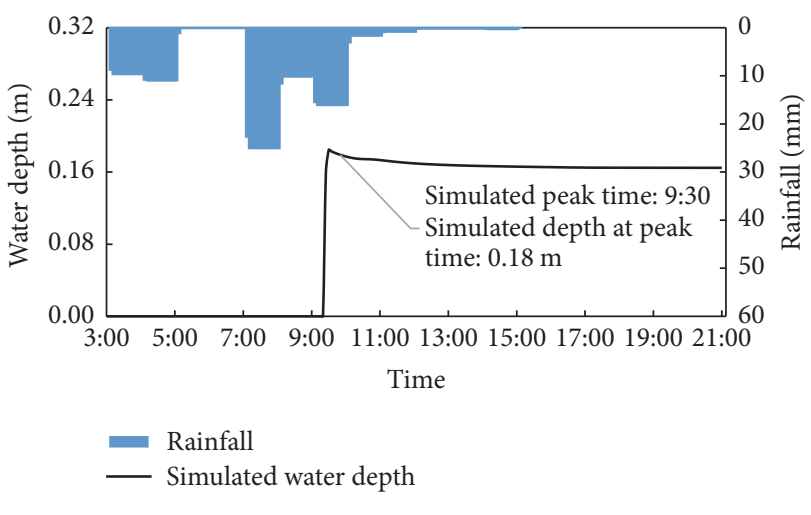

(b) The simulated water depth hydrograph for 2013-07-23 rainfall event

FIGURE 2: Hydrograph of water depth at the road station for historical rainfall events.

TABLE 4: Characteristics and areas for different risk levels of historical and designed rainfall events, respectively.

\begin{tabular}{|c|c|c|c|c|c|c|}
\hline \multirow{2}{*}{$\begin{array}{l}\text { Designed rainfall \& } \\
\text { historical rainfall }\end{array}$} & \multirow{2}{*}{$\begin{array}{l}\text { Total rainfall } \\
\qquad(\mathrm{mm})\end{array}$} & \multirow{2}{*}{$\begin{array}{l}\text { Maximum hourly rainfall } \\
\text { intensity }\left(\mathrm{mm} \cdot \mathrm{h}^{-1}\right)\end{array}$} & \multicolumn{4}{|c|}{ Flood risk area $\left(\mathrm{hm}^{2}\right)$} \\
\hline & & & Low & Moderate & Significant & Extreme \\
\hline$P=1$ & 26.7 & - & 98.9 & 0.3 & 0.7 & 0.2 \\
\hline$P=5$ & 38.84 & - & 97.6 & 0.5 & 1.6 & 0.5 \\
\hline$P=10$ & 44.06 & - & 96.8 & 0.6 & 2.2 & 0.5 \\
\hline$P=20$ & 49.29 & - & 95.9 & 0.6 & 3.1 & 0.6 \\
\hline $2013-07-23$ & 71.3 & 22.9 & 99.0 & 0.3 & 0.7 & 0.2 \\
\hline 2015-08-03 & 62.1 & 39.6 & 97.5 & 0.5 & 1.7 & 0.4 \\
\hline
\end{tabular}

Owing to the instrument problem, only the maximum water depth $(0.13 \mathrm{~m})$ and the corresponding occurrence time (9:06) have been recorded for 2013-07-23 rainfall event; those of the simulation are $0.18 \mathrm{~m}$ and 9:30 (see Figure 2(b)). It can be noticed that the difference of the maximum water depth and the occurrence time between simulation and observation is small. Through calibration and validation, it is concluded that the model has well represented the historical rainfall events with reasonable accuracy and confidence.

4.2. Road Flood Risk Zoning. Now that the model shows good performance, it can be applied for urban flood simulation and risk zoning. The model is used for running with four designed rainfall scenarios (rainfall duration is $120 \mathrm{~min}$ and recurrence intervals are $1,5,10$, and 20 years) generated with the InfoWorks ICM (as shown in Figure 3). The timevariable water depth and velocity for every calculating grid are obtained and used to calculate flood risk with the formula in Section 2. And the maximum risk value for each grid along the simulating period is obtained. The risk level for each risk value can be calculated referring to Table 2 with which the risk zoning maps are generated and shown in Figures 4 and 5. Areas with low, moderate, significant, and extreme risk are summarized in Table 4.

Table 4 shows that, with the increase of rainfall recurrence intervals, the total area of low risk gradually decreases while the total area of the risk above moderate gradually increases

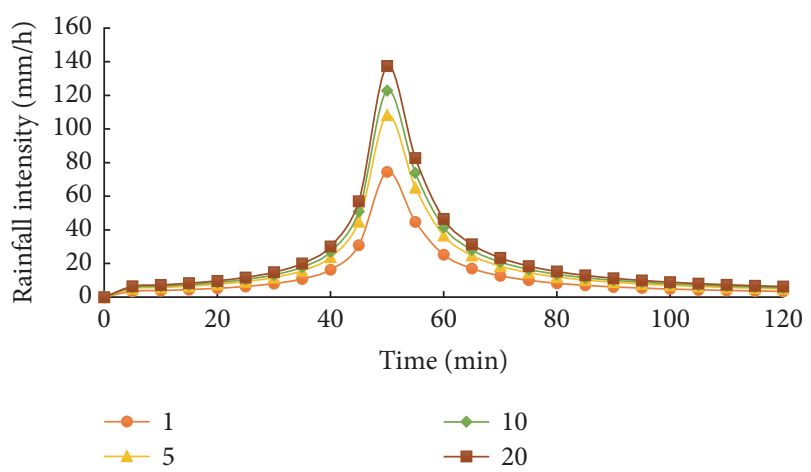

FIGURE 3: Hydrograph of the designed rainfall events.

on the contrary. The total rainfall of 2013-07-23 event is greater than that of 2015-08-03 event, whereas the latter has a larger maximum hourly rainfall than the former. It can be found that the area of low risk for the former is larger than the latter while the former has a larger area of risk above moderate.

4.3. Discussion. (1) It can be seen from Figure 2 that the simulation shows some discrepancy with the observation. The simulation results of the two historical rainfall events show that almost no water accumulates before about 9:20 


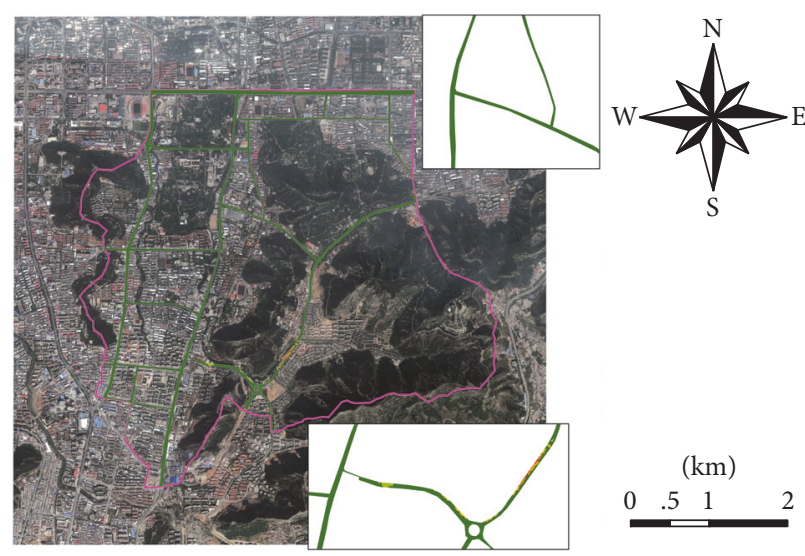

$$
\begin{array}{r}
\text { Risk } \\
1 \\
2 \\
3
\end{array}
$$

(a) Flood risk zoning for 2013-07-23 rainfall event
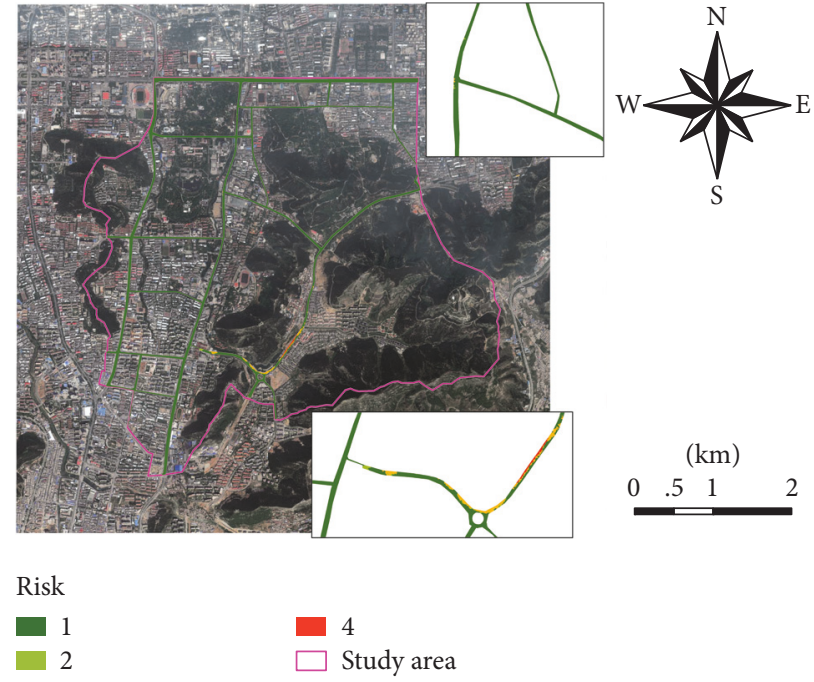

(b) Flood risk zoning for 2015-08-03 rainfall event

FIGURE 4: Flood risk zoning for historical rainfalls.

and 19:50, respectively, whereas the water depth quickly rises afterwards. The observed water depth for 2015-08-03 rainfall event shows a fluctuation before reaching the peak and then inclines quickly (as depicted in Figure 2(a)). There are two reasons accounting for this phenomenon. First, the runoff of the subcatchments converges into manholes without flowing through the surface in the early time. As a consequence, no water will accumulate on the surface before the pipe networks become surcharged. Second, the interval of the rainfall data used here is one hour, which means the rainfall intensity is constant from 19:00 to 20:00. Therefore, the simulated surface inundation depth increases gradually. However, the actual rainfall intensity for historical rainfall events varies along time, which generates the fluctuated dashdotted line in Figure 2(a). It is deduced that if fully twodimensional hydrodynamic simulation is carried out with computationally powerful computers and the rainfall data intervals are smaller (such as 5 min intervals), the simulation results will be better in line with the observations.

(2) It can be noted from Section 4.2 that the flood risk zoning results show that the area of risk above moderate for 2013-07-23 rainfall event (more rainfalls) is smaller than that for 2015-08-03 rainfall event (fewer rainfalls). This is mainly because the latter has a larger maximum hourly rainfall intensity. Moreover, the former has two rainfall peaks and the distribution is more even, while the latter has only one rainfall peak which is centralized. Owing to the limited capacity of the underground drainage system, surcharged water will induce surface inundation if excessive rains flow into the drainage system within a short time. For the 2013-07-23 rainfall event, the light rain after the first rainfall peak makes it easier for drainage capacity restoration, while the 2015-0803 rainfall event has an earlier rainfall peak which is relatively concentrated. For the 2015-08-03 event, the drainage pipes are overloaded all the time without enough time for their capacity restoration, and therefore the surface is flooded by the excessive water from manholes.

\section{Conclusions}

This paper presents a study on urban flood risk in the "Sponge City Construction" pilot area of Jinan City. In this study, the InfoWorks ICM model is used to simulate two historical rainfall events and four designed rainfalls with different recurrence intervals. The surface water depth and flood velocity are recorded. The model is verified with flood monitoring records and its applicability is proved. Possible causes resulting in model errors are analyzed. Then, the recorded water depth and flood velocity are utilized to estimate the flood risk and perform flood risk zoning. Through analysis and discussion on the results, the following conclusions are drawn:

(1) The coupled model developed in this study well simulates the historical rainstorm events with good confidence and accuracy. Although the simulated water depth and occurrence time of the peak for 201307-23 rainfall event show a little discrepancy with the observed record, the result is reasonable. The simulating maximum water depth and the occurrence time for 2015-08-03 rainfall event are almost entirely the same as the observed records, although the hydrographs of water depth are not completely consistent.

(2) There are two main reasons accounting for the inconsistence of the hydrograph between simulation and observation for 2015-08-03 rainfall event. First, the hydrological modeling cannot simulate the surface inundation, so the surface will not get flooded until the pipes become overloaded. Second, the rainfall data used in this study is hourly interval and the 

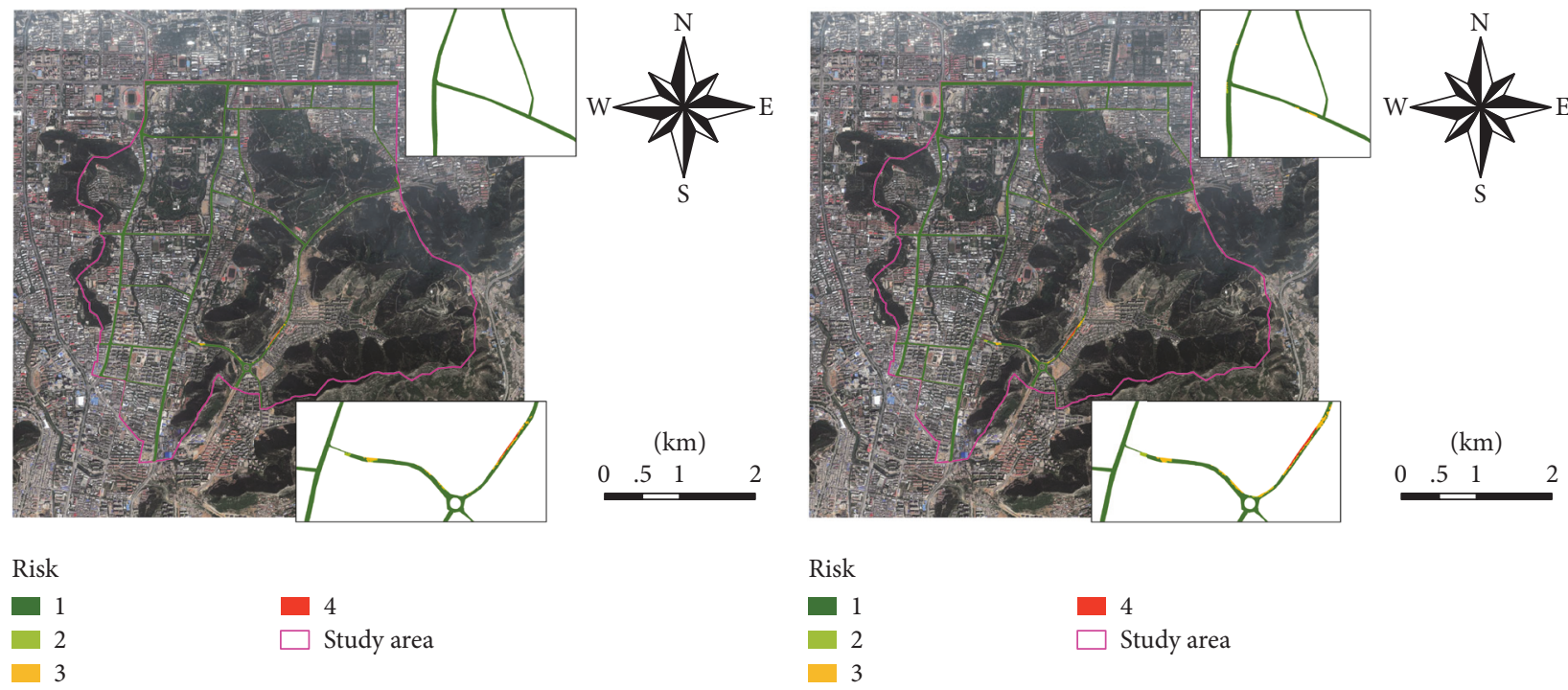

(a) Flood risk zoning for 1-year designed rainfall
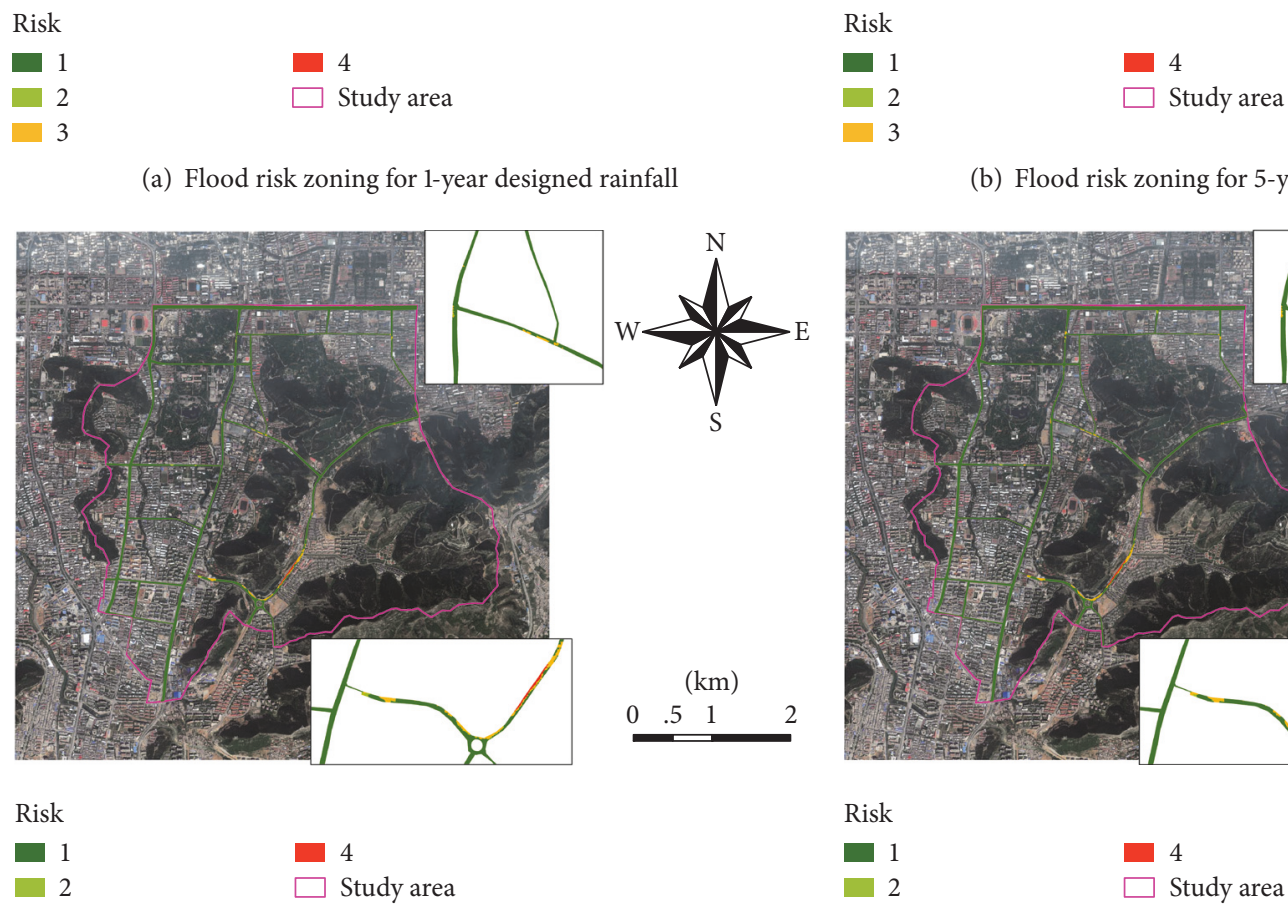

(b) Flood risk zoning for 5-year designed rainfall
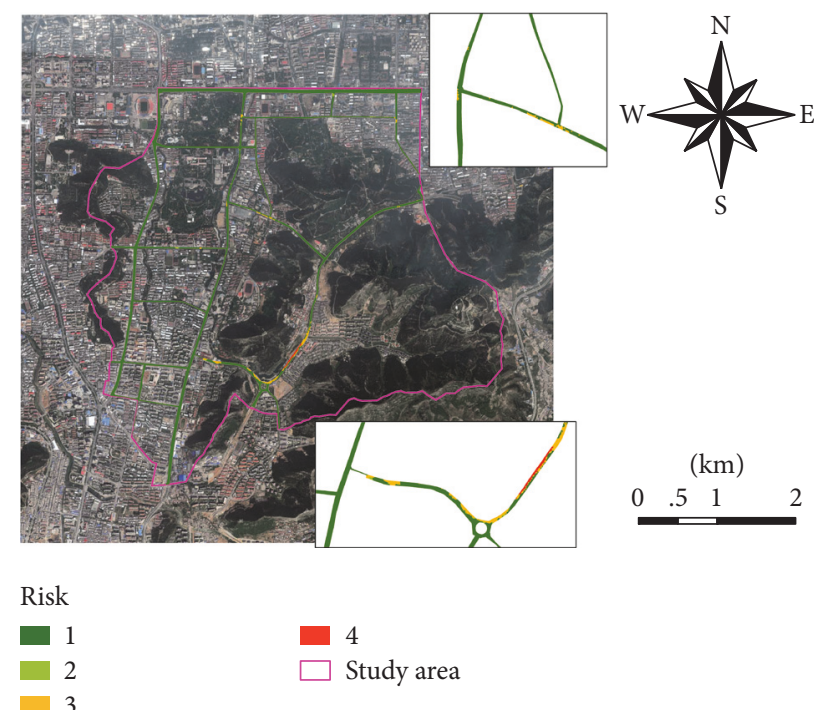

(c) Flood risk zoning for 10-year designed rainfall

(d) Flood risk zoning for 20-year designed rainfall

FIgURE 5: Flood risk zoning for designed rainfalls.

rainfall intensity is even in an hour, which results in the gradual increase and decrease of the hydrograph. However, the actual rainfall may change frequently and rapidly, resulting in the fluctuation of the observed surface water depth.

(3) The flood risk zoning results of the historical and designed rainfall events show that rainfall with larger recurrence intervals will produce larger areas of risk above moderate. The simulation results of the two historical rainfall events indicate that if the maximum hourly rainfall intensity is smaller and the rainfall distribution is more even, the area of risk above moderate is smaller. This is mainly because the pipes will not easily get surcharged to make manholes overflow under this condition. This conclusion is very constructive to the flood control work. Water storage devices (e.g., pond, valley dam) can be set up at the mountain fronts, and water collecting devices such as Rain Barrels can be placed in the residential area. These measures will help collect rainwater in the early raining time, which alleviates drainage pressure, thereby avoiding urban flooding.

\section{Conflicts of Interest}

The authors declare that they have no conflicts of interest. 


\section{Acknowledgments}

This work was financially supported by the National Natural Science Foundation of China (Grant no. 51579007). The authors would also like to acknowledge the financial support of the project named Water Cycle and Hydrological Process Modeling of Jinan "Sponge City."

\section{References}

[1] T. Cheng, Z. Xu, and S. Song, "Rainfall-runoff simulations for Xinglong sponge city pilot area of Jinan," Journal of Hydroelectric Engineering, vol. 36, no. 6, pp. 1-11, 2017.

[2] J. Liu and C. Zhang, "Identification of risks and estimation of flood storage in ponds," Mathematical Problems in Engineering, vol. 2017, pp. 1-9, 2017.

[3] M. J. Hammond, A. S. Chen, S. Djordjević, D. Butler, and O. Mark, "Urban flood impact assessment: A state-of-the-art review," Urban Water Journal, vol. 12, no. 1, pp. 14-29, 2015.

[4] E. Salvadore, J. Bronders, and O. Batelaan, "Hydrological modelling of urbanized catchments: A review and future directions," Journal of Hydrology, vol. 529, no. 1, pp. 62-81, 2015.

[5] J. Yin, D. Yu, Z. Yin, M. Liu, and Q. He, "Evaluating the impact and risk of pluvial flash flood on intra-urban road network: A case study in the city center of Shanghai, China," Journal of Hydrology, vol. 537, pp. 138-145, 2016.

[6] J. Yin, D. Yu, and R. Wilby, "Modelling the impact of land subsidence on urban pluvial flooding: A case study of downtown Shanghai, China," Science of the Total Environment, vol. 544, pp. 744-753, 2016.

[7] J. Xie, H. Chen, Z. Liao, X. Gu, D. Zhu, and J. Zhang, "An integrated assessment of urban flooding mitigation strategies for robust decision making," Environmental Modelling \& Software, vol. 95, pp. 143-155, 2017.

[8] W. Hu, W. He, G. Huang, and J. Feng, "Review of urban storm water simulation techniques," Advances in Water Science, vol. 21, no. 1, pp. 137-144, 2010 (Chinese).

[9] X. Wu, Z. Wang, S. Guo, W. Liao, Z. Zeng, and X. Chen, "Scenario-based projections of future urban inundation within a coupled hydrodynamic model framework: A case study in Dongguan City, China," Journal of Hydrology, vol. 547, pp. 428442, 2017.

[10] Q. Huang, J. Wang, M. Li, M. Fei, and J. Dong, "Modeling the influence of urbanization on urban pluvial flooding: a scenariobased case study in Shanghai, China," Natural Hazards, vol. 87, no. 2, pp. 1035-1055, 2017.

[11] Y. Fan, T. Ao, H. Yu, G. Huang, and X. Li, "A coupled 1D-2D hydrodynamic model for urban flood inundation," Advances in Meteorology, vol. 2017, pp. 1-12, 2017.

[12] W. Huber, J. Heaney, M. Medina, W. Peltz, and H. Sheikh, Storm Water Management Model: User's Manual, 2nd edition, 1975.

[13] J. Teng, A. J. Jakeman, J. Vaze, B. F. W. Croke, D. Dutta, and S. Kim, "Flood inundation modelling: A review of methods, recent advances and uncertainty analysis," Environmental Modelling \& Software, vol. 90, pp. 201-216, 2017.

[14] H. Yu, G. Huang, and C. Wu, "Application of the stormwater management model to a piedmont city: A case study of Jinan City, China," Water Science and Technology, vol. 70, no. 5, pp. 858-864, 2014.

[15] G. Huang, X. Wang, and W. Huang, "Simulation of rainstorm water logging in urban area based on InfoWorks ICM model," Water Resources and Power, vol. 34, no. 2, pp. 66-70, 2017.
[16] H. Wu and G. Huang, "Risk assessment of urban waterlogging based on PCSWMM model," Water Resources Protection, vol. 32, no. 5, pp. 11-16, 2016.

[17] Q. Chu, D. Peng, Z. Xu, D. Meng, T. Zhen, and Q. Jiang, "Risk analysis of urban flooding by using MIKE11 and MIKE21," Journal of Beijing Normal University (Natural Science), vol. 50, no. 5, pp. 446-451, 2014.

[18] J. Xia, R. A. Falconer, Y. Wang, and X. Xiao, "New criterion for the stability of a human body in floodwaters," Journal of Hydraulic Research, vol. 52, no. 1, pp. 93-104, 2014.

[19] J. Xia, Q. Chen, R. A. Falconer, S. Deng, and P. Guo, "Stability criterion for people in floods for various slopes," in Institution of Civil Engineers-Water Management, Thomas Telford Ltd., UK, 2015.

[20] L. Milanesi, M. Pilotti, and R. Ranzi, "A conceptual model of people's vulnerability to floods," Water Resources Research, vol. 51, no. 1, pp. 182-197, 2015.

[21] L. Milanesi, M. Pilotti, and B. Bacchi, "Using web-based observations to identify thresholds of a person's stability in a flow," Water Resources Research, vol. 52, no. 10, pp. 7793-7805, 2016.

[22] H. Wallingford, R\&D outputs: flood risks to people: phase 2: the flood risks to people methodology, 2006.

[23] H. Wallingford, Innovyze. InfoWorks ICM Help v3.0. 2012: UK.

[24] G. Huang, "Urban Storm Water Model and its Application," in China Water \& Power Press, Beijing, 2013.

[25] C. Song, H. Wang, and J. Shang, "Study on application of InfoWorks CS to Xiangshan area in Beijing," Water Resources and Hydropower Engineering, vol. 45, no. 7, pp. 13-17, 2014.

[26] G. Zhao, R. Shi, B. Pang, Z. Xu, L. Du, and X. Chang, "Impact of rapid urbanization on rainfall-runoff processes in urban catchment case study for Liangshui river basin," Journal of Hydroelectric Engineering, vol. 35, no. 5, pp. 55-64, 2016. 


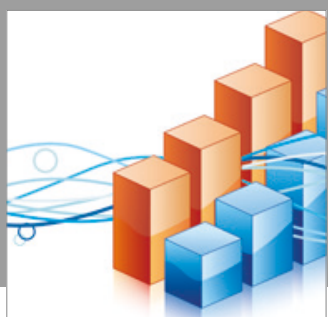

Advances in

Operations Research

vatersals

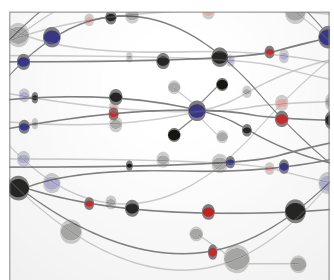

\section{The Scientific} World Journal
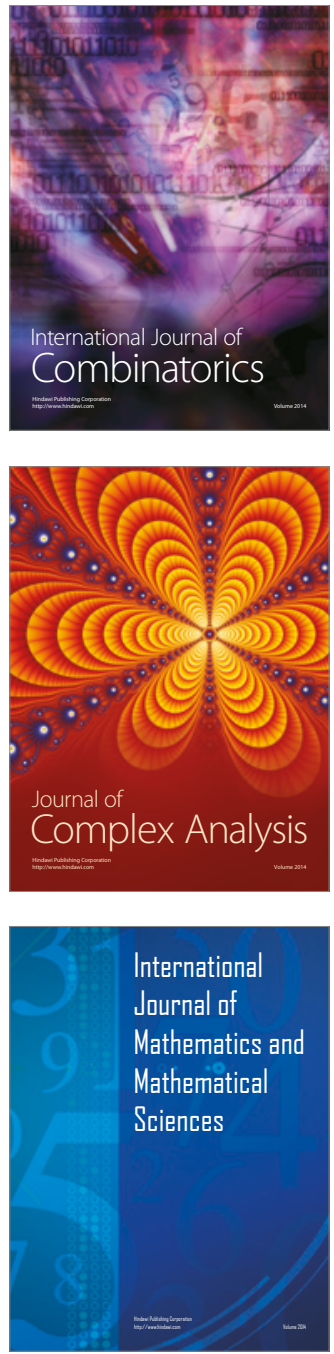
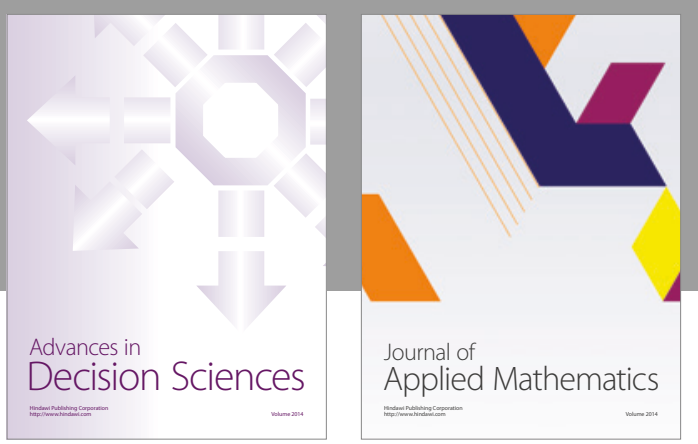

Algebra

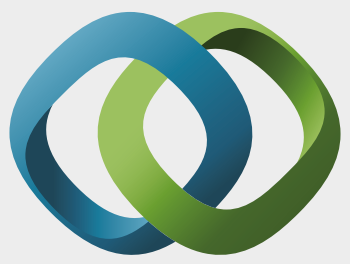

\section{Hindawi}

Submit your manuscripts at

https://www.hindawi.com
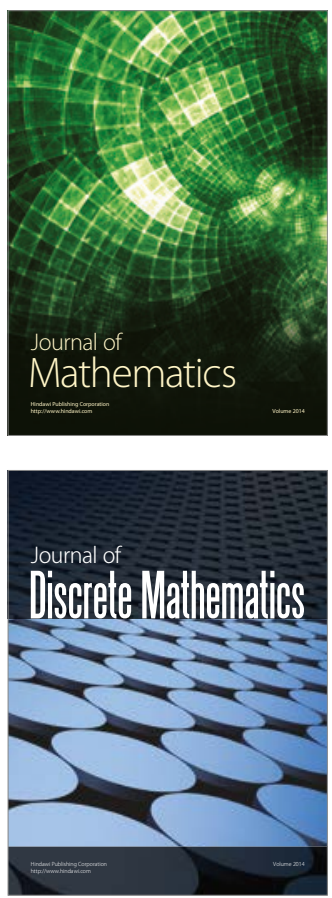

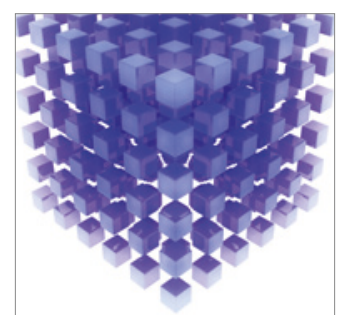

Mathematical Problems in Engineering
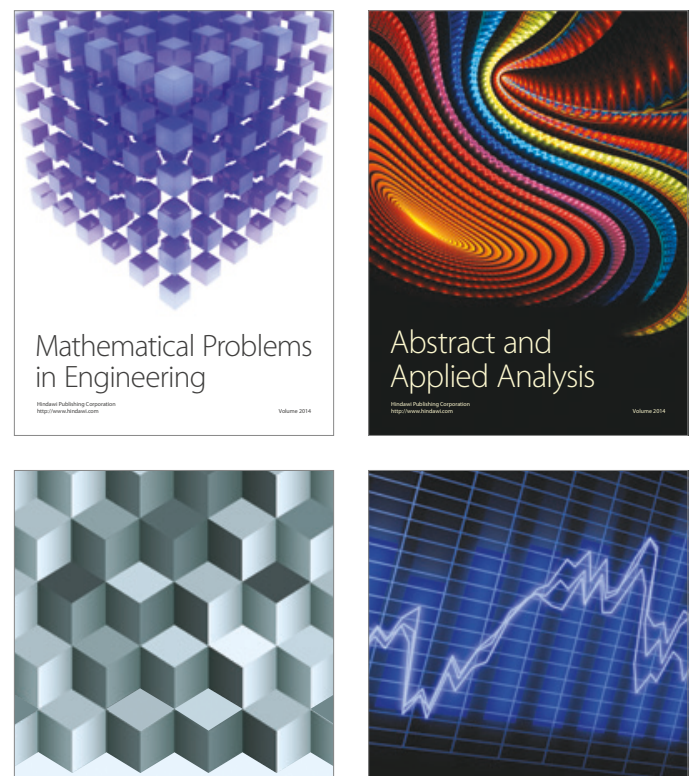

Journal of

Function Spaces

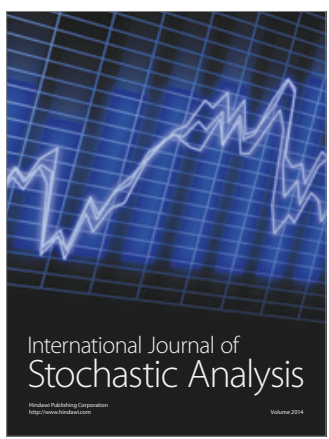

Probability and Statistics
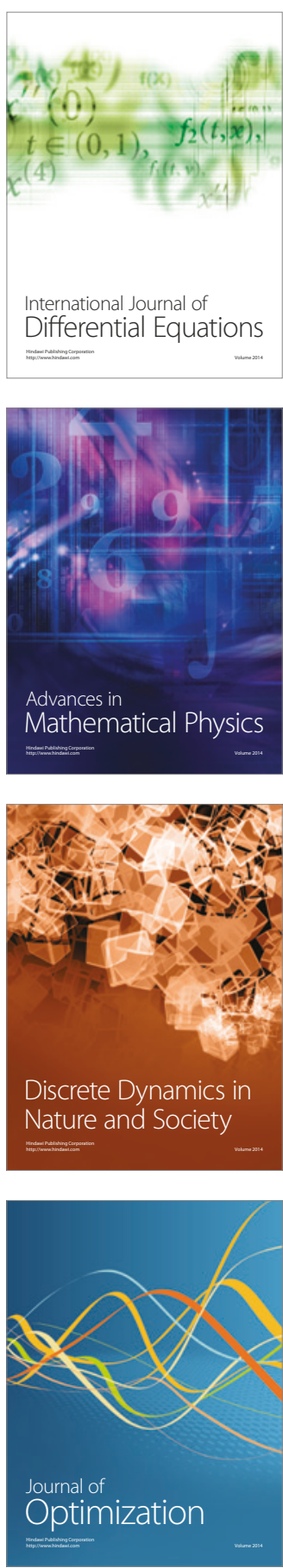